\title{
DŽOZEF ANTON SALMANA RUŽDIJA: IZMEĐU MEMOARA, AUTOBIOGRAFIJE I AUTOPOETIKE
}

Polazeći od žanrovske hibridnosti Ruždijevog fikcionalnog opusa, u radu se razmatra osobena žanrovska mešavina njegove memoarske proze Džozef Anton (2012), kao dela koje zamagljuje razliku između tradicionalnih memoara i autobiografije, sadrži neočekivane pasaže koji ovu knjigu približavaju autorovim fikcionalnim tekstovima, a služi piscu i kao prilika da rezimira i rekapitulira svoje osnovne književne poglede i (auto)poetičke preokupacije.

Ključne reči: Salman Ruždi, memoari, autobiografija, poetika.

U ovom radu bavimo se knjigom memoarske proze savremenog anglofonog pisca Salmana Ruždija (Salman Rushdie), objavljenom 2012. godine pod naslovom Džazef Anton: Memoari (Joseph Anton: A Memoir). ${ }^{1}$ Na stranama koje slede razmotrićemo specifičnu žanrovsku mešavinu kojom se ovi memoari odlikuju, njihove dodirne tačke sa Ruždijevim fikcionalnim delima, a posebno eksplicitne poetičke iskaze koji su u njih ugrađeni i koji osvetljavaju celokupni Ruždijev opus.

Ruždijev prepoznatljivi autorski rukopis podrazumeva upadljivu mešavinu žanrovskih obrazaca - prvenstveno realizma i fantastike

1 U referencama na knjigu koristimo skraćenice $J A$ za engleski izvornik, odnosno DŽA za objavljeni prevod. S obzirom na pretežno nezadovoljavajući kvalitet postojećeg srpskog prevoda, prilikom navođenja citata obično dajemo sopstveni prevod, a referencu na odgovarajuće mesto u prevodu navodimo u uglastim zagradama. 
(Ruždi se smatra jednim od glavnih predstavnika „magičnog realizma”), ali i ozbiljnog i smešnog, satire i melodrame, bajke i groteske. Takva mešavina žanrova karakteristična je za savremenu književnost uopšte, a posebno za roman kao formu. Pa ipak, Ruždi je izrazit predstavnik ,transžanrovske” proze, a svoje opredeljenje je u više navrata i eksplicitno izneo u nefikcionalnim tekstovima. Najskoriji primer je predgovor za antologiju priča dvanaest savremenih anglofonih i hispanskih pisaca, objavljenu povodom četiristote godišnjice Šekspirove (William Shakespeare) i Servantesove (Miguel de Cervantes) smrti, u kome Ruždi ukazuje da ovim slavnim književnim velikanima dugujemo „uverenje da književno delo ne mora da bude prosto komično, ili tragično, ili romantično, ili političko / istorijsko: odnosno da ono, ako je osmišljeno kako valja, može da bude više različitih stvari istovremeno" (Rushdie 2016: 8). ${ }^{2}$ Ruždi u svojoj oceni zapravo rezimira i usvaja romantičarsko shvatanje Šekspira kao uzornog „nečistog” pisca koji u svojim dramskim delima slobodno meša „visoke” i „niske” elemente, pri čemu se njegovi komadi odlikuju organskim jedinstvom iako se ne pridržavaju klasicističkih pravila: „Evo šta smo od Barda nasledili mi koji dolazimo posle njega: znanje da jedno delo može da bude sve u isti mah. Francuska tradicija, koja je stroža, razdvaja tragediju (Rasin) i komediju (Molijer). Šekspir ih meša i spaja, a zahvaljujući njemu, možemo i mi” (RusHDIE 2016: 9). ${ }^{3}$

Kad je reč o Ruždijevom opusu kao celini, slažemo se sa ocenom kritičarke Jael Maurer (Yael Maurer) koja zapaža da je upravo „njegova žanrovska hibridnost, ili odbijanje da se uklopi u neku jasno

2 " $[\ldots]$ the belief that a work of literature doesn't have to be simply comic, or tragic, or romantic, or political / historical: that, if properly conceived, it can be many things at the same time." Svi citati iz izvornika dati su u mom prevodu, osim ukoliko nije drugačije naznačeno.

3 "This is what we who come after inherit from the Bard: the knowledge a work can be everything at once. The French tradition, more severe, separates tragedy (Racine) and comedy (Molière). Shakespeare mashes them up together, and so, thanks to him, can we." Ovu teoriju formulisao je August Šlegel (August Schlegel), od koga ju je preuzeo i u engleskoj kritici definitivno afirmisao Kolridž (Samuel Taylor Coleridge), u predavanju o Sekspiru iz 1811. godine (v. ORSINI 1964). 
određenu žanrovsku kategoriju [...] ono što ga čini toliko osobenim” (MAurer 2014: 177). ${ }^{4}$ Zanimljivo je, međutim, da i Ruždijevi memoari, iako nefikcionalno delo od koga bismo očekivali objektivnost i dokumentarizam, predstavljaju neočekivani spoj raznorodnih žanrovskih elemenata, što je odmah privuklo pažnju akademske književne kritike, uključujući i njihovo smelo tumačenje iz pera Jael Maurer na koje ćemo se vratiti nešto kasnije.

U specifičnoj kombinaciji elemenata koji se ukrštaju u Džozefu Antonu, možda je najmanje neobično Ruždijevo mešanje tradicionalnih obeležja memoara i autobiografije. Kad je o ova dva srodna žanra reč, u teoriji se obično povlači razlika između „spoljašnje orijentacije res gestae i memoara, u kojima se pojedinac prikazuje kao društveni tip”, nasuprot autobiografiji, koja je „usredsređena na sećanje i identitet [...]. Samo je autobiografija usmerena na lični identitet, dok je svrha memoara da potvrde autorovo mesto u svetu" (SchWALm 2014: par. 14). ${ }^{5}$ Najjezgrovitije rečeno, osnovna razlika ogleda se u tome što pisac $\mathrm{u}$ autobiografiji uglavnom govori o sebi, a u memoarima - o drugima (Popović 2010: 423; Schwalm 2014: par. 1). Za autobiografiju je karakteristična priča o formiranju autorove ličnosti, "Bildungsgeschichte", a u slučaju pisaca, tesna veza između autorovog života i književnog dela (Schwalm 2014: par. 2). Osim toga,

kao književni žanr, autobiografija označava retrospektivni narativ u kome se pripoveda priča o autorovom sopstvenom životu, ili nekom njegovom značajnom delu, sa željom (barem u klasičnoj verziji) da se rekonstruiše njegov ili njen lični razvoj u datom istorijskom, društvenom i kulturnom kontekstu (Schwalm 2014: par. 1). ${ }^{6}$

4 "[...] its generic hybridity, or its refusal to fit into a neat generic category, is what makes it so much his own."

5 " $[. .$.$] the external orientation of res gestae and memoir, representing the indi-$ vidual as social type, on the one hand, as opposed to autobiography with its focus on memory and identity [...], on the other hand. Only autobiography aims at personal identity whereas the memoir is concerned with affirming the autobiographer's place in the world."

6 " $[. .$.$] autobiography as a literary genre signifies a retrospective narrative that un-$ dertakes to tell the author's own life, or a substantial part of it, seeking (at least 
Međutim, granice između ovih žanrova su zamagljene i među njima postoji visok stepen interakcije (Schwalu 2014: par. 25), a Ruždijevi memoari mogu da posluže kao ilustrativan primer takvog preklapanja.

S jedne strane, Ruždijev Džozef Anton je uglavnom knjiga o njemu samom, koja se bavi pitanjima autorovog identiteta i obuhvata retrospektivnu autobiografsku naraciju, „sa željom da se rekonstruiše njegov lični razvoj”. To se posebno odnosi na prvo poglavlje knjige, posvećeno prošlosti, kao i na neke kraće kasnije pasaže, ali i na delo kao celinu, jer se u njemu, pored ostalog, opisuje piščev lični razvitak tokom odsudnog razdoblja u njegovom životu. S druge strane, Džozef Anton svakako deli i uobičajenu svrhu memoara, koji treba "da potvrde autorovo mesto u svetu" i prikažu ga kao određeni društveni tip. Možda bi zato bilo najpreciznije reći da su u pitanju memoari sa naglašenim autobiografskim elementima.

Ruždijevi memoari su u prvom redu koncipirani kao detaljan hronološki pregled afere izazvane njegovim romanom Satanski stihovi (The Satanic Verses), dat iz piščeve perspektive, koji pokriva vremenski period od javnog izricanja fatve, 14. februara 1989, do proleća 2002. godine. Ova komponenta memoara je dokumentaristička i faktografska. Otprilike trećina knjige najsličnija je dnevničkim zapisima, sa obiljem podataka o raznim ličnostima sa kojima se Ruždi sretao i mestima na kojima je boravio u toku kampanje koju je vodio u svoju odbranu. ${ }^{\gamma}$ Pri tome je lična dimenzija apsolutno dominantna, jer Ruž ${ }^{-}$ di u tu osnovnu potku uključuje i brojna ogovaranja, bračne trzavice, kalkulacije i mahinacije izdavačkih kuća, političku kombinatoriku

in its classic version) to reconstruct his/her personal development within a given historical, social and cultural framework."

7 Ruždijevi memoari su po svoj prilici i proistekli upravo iz materijala te vrste. Naime, Ruždi je još 1992. napomenuo da vodi takve dnevničke beleške (CHAUHAN 2001: 119). Osim toga, drugi deo njegove knjige eseja Predi ovu crtu (Step Across This Line), naslovljen „Poruke iz godina kuge” (Messages from the Plague Years," RushDiE 2002: 211-258), obuhvata 19 kraćih autobiografskih zapisa, beleški, članaka, pisama i Ruždijevih izjava iz vremena njegove kampanje protiv fatve (1992-1997), koji se dobrim delom preklapaju sa građom uključenom u kasnije objavljene memoare. 
zvaničnika i svadljive polemike sa drugim piscima zbog najrazličitijih povoda, mada najčešće zbog svoje povređene sujete. Imajući u vidu ovaj aspekt knjige, Robert Iglston (Robert Eaglestone) smatra da $D \check{z} 0^{-}$ zef Anton predstavlja „posebnu formu memoara”, odnosno svojevrsnu piščevu arhivu, što po njegovom sudu ujedno objašnjava i Ruždijevu potrebu svođenja računa sa svima, jer, kako Iglston ukazuje, „u istoriji je, začudo, arhiva ta koja stvara istorijski dogadaj”, a ne obratno (EAGLESTONE 2013: 120). ${ }^{8}$

Ipak, ono što Džozefa Antona čini zanimljivom knjigom nije samo arhivska građa, pa ni uvid koji nam ona pruža u Ruždijev život tokom njegovih „godina koje su pojeli skakavci”, provedenih pod zaštitom bezbednosnih službi. Kad je reč o autobiografskoj dimenziji, najvrednijom smatramo retrospektivnu naraciju u okviru prvog poglavlja knjige, gde pisac ukratko opisuje svoje poreklo, porodicu, odrastanje, formiranje svoje ličnosti, godine školovanja u Engleskoj i razvoj svoje spisateljske karijere, navodeći mnoge pojedinosti koje ranije nisu bile dostupne čitaocima (JA 17-91, DŽA 21-91). Tome treba dodati i još jedan kasniji autobiografski pasaž u kome Ruždi govori o ocu, majci, sestrama, njihovim međusobnim odnosima i prvim brakovima svojih roditelja (JA 565-569, DŽA 534-537). Memoari u tom pogledu predstavljaju značajan izvor biografskih podataka o Ruždiju, koji su se do njihovog objavljivanja uglavnom mogli pronaći samo u piščevim uzgrednim opaskama iznetim u nekim od eseja i intervjua, ili u šturim „hronologijama” njegovog života i rada uključenim u većinu kritičkih monografija i zbornika radova. ${ }^{9}$

Autobiografski elementi nisu sami po sebi naročito neobičan sastojak bilo čijih memoara. Međutim, postoje neke zanimljive dodirne tačke između Džozefa Antona i Ruždijevih fikcionalnih dela, među ko-

8 "oddly, in history, the archive creates the historical event."

9 Izuzetak predstavlja za sada jedina ,autorizovana” Ruždijeva biografija, članak Ijana Hamiltona (Ian Hamilton) „Prvi život Salmana Ruždija” “The First Life of Salman Rushdie," Hanilтon 1998: 95-138), koji je prvobitno objavljen u američkom časopisu Njujorker (New Yorker, 25 December 1995 \& 1 January 1996: 90113). Uz piščeve memoare, ovaj tekst do danas ostaje najdetaljniji izvor informacija o Ruždijevom životu do 1989. godine. 
jima je najuočljivija upravo autobiografska dimenzija. Naime, autobiografija je često izvorište Ruždijeve fikcije, uključujući njegove najpoznatije romane, Deca ponoći (Midnight's Children), Satanski stihovi i Mavrov poslednji uzdah (The Moor's Last Sigh), koji svi sadrže mnoštvo autobiografskih elemenata. ${ }^{10}$ Dva od ovih romana, Deca ponoći i Mavrov poslednji uzdah, i po formi su fiktivne autobiografije pripovedača. U isti mah, Ruždi takoreći od početka svoje karijere upozorava na pogubnu sklonost da se fikcionalna dela pretvore u prikrivenu autobiografiju. On tako još 1987, u prikazu Najpolovog (V. S. Naipaul) romana Enigma dolaska (The Enigma of Arrival), koji po Ruždijevom sudu predstavlja izraz autorove iscrpljenosti, iznosi opštu, negativno intoniranu opasku da piscu, „kada [mu] ponestane snage za fikciju, preostaje autobiografija” (Rushdie 1992: 150). ${ }^{11}$ Sasvim u skladu sa tom ocenom, Ruždi se oduvek protivi autobiografskom tumačenju svojih knjiga, tvrdeći da njegovi romani pre funkcionišu kao svojevrsno bekstvo od autobiografije (REDER 2000: 122). ${ }^{12}$ Ruždi je takođe u više prilika isticao da nikada nije stvorio nijedan zaista autobiografski lik, naglašavajući da ga ne treba poistovećivati sa glavnim likovima njegovih romana i da nikada nije razumeo takvu sklonost kritičara. U Džozefu Antonu, Ruždi povodom romana Bes piše:

kod njegovog Malika Solanke, anomija i mrzovolja su bile namerno razvijene da bi ga odvojile od njegovog tvorca. [...] Saladin Čamča iz Satanskih stihova

10 Ruždijevi eseji i drugi nefikcionalni tekstovi takođe sadrže česte autobiografske ekskurse, zbog kojih su i pojedini među njima značajni kao izvor podataka o piščevom životu.

11 " $[. .$.$] when the strength for fiction fails the writer, what remains is autobiogra-$ phy."

12 V. takođe ReDer 2000: 32, 36, gde Ruždi komentariše razlike koje postoje između njega i pripovedača Dece ponoći Salima Sinaja, objašnjava da je njegova porodica sasvim drugačija od Salimove i da knjiga nije autobiografska, a da je dobila svoju sadašnju formu počev od onog trenutka kada je Salim „progovorio” u prvom licu, što je omogućilo da se obimna građa održi na okupu. Upor. takođe sličnu Ruždijevu tvrdnju u vezi sa autobiografskim elementima u romanu Mavrov poslednji uzdah, da je priča zaživela tek pošto mu je pošlo za rukom da se odvoji od autobiografske pozadine. Citirano u KunRTTI 2012: 76. 
Srđan Simonović: Džozef Anton Salmana Ruždija: izmedu memoara, autobiografije...

takođe je predstavljao pokušaj da se stvori lik koji mu je suprotan, kao njegovo anti-ja, i bilo je čudno da su u oba slučaja ove likove, koje je osmislio kao drugačije od sebe, mnogi protumačili kao proste autoportrete. Ali Stiven Dedalus nije Džojs, kao što ni Hercog nije Belou, ni Cukerman Rot, niti je Marsel Prust; pisci odvajkada obavljaju svoj posao u blizini bika, kao matadori, igrajući složene igre sa autobiografijom, ali su njihove kreacije ipak zanimljivije od njih samih (JA 596; [DZ̆A 562-563]). ${ }^{13}$

Osim autobiografskih tumačenja, kritičari često zameraju Ruždiju da povlađuje sebi tako što se zaklanja iza lika pripovedača, a ponekad i drugih likova, da bi preko njih progovarao u sopstveno ime. Izvesno je da se radi o njegovoj latentnoj sklonosti (i slabosti) koja postoji barem od Dece ponoći. ${ }^{14}$ Ruždi priznaje da je „piscu vrlo lako da ima figuru

13 "[... his Malik Solanka's anomie and grouchiness was intentionally developed to separate him from his creator. [...] Saladin Chamcha in The Satanic Verses had been another attempt to create an anti- or opposite-self, and it was puzzling that in both cases these characters whom he had written to be other than himself were read by many people as simple self-portraits. But Stephen Dedalus was not Joyce, and Herzog was not Bellow, and Zuckerman was not Roth, and Marcel was not Proust; writers had always worked close to the bull, like matadors, had played complex games with autobiography, and yet their creations were more interesting than themselves."

${ }_{14}$ Na primer, Prija Đoši (Priya Joshi), posle konstatacije da je teško razlikovati Ruždijev glas od Salimovog, zaključuje da zamagljivanje razlike između pisca i pripovedača u celom Ruždijevom opusu uopšte nije neuobičajeno (Joshi 2002: 244, 298n27), dok Keri-Džejn Volart (Kerry-Jane Wallart), pišući o romanu Čarobnica iz Firence (The Enchantress of Florence), primećuje da pripovedač, čak i kada postoji fokalizacija, kao da uvek „maše čitaocu” iz teksta ("[...] the narrator waving at the reader”, WALLART 2011: 218). Najžešća kritika ove Ruždijeve sklonosti možda je sud Pankađa Mišre (Pankaj Mishra), iznet u prikazu Tla pod njenim nogama, po kome Ruždijeva poetika svodi roman na monolog pisca/pripovedača, što posebno dolazi do izražaja u njegovim kasnijim delima, koja se pretvaraju u anti-romane, „svaštare” koje piscu služe kao ventil za saopštavanje ličnih „opsesija, predrasuda i pristrasnosti" ("miscellanies", "obsessions, his prejudices and biases", MisHrA 1999: n. pag.). Mišra smatra da je Ruždi ovu strategiju preuzeo iz Grasovog Limenog doboša (Günter Grass, Die Blechtrommel), dok nas ovaj postupak pre podseća na Sola Beloua (Saul Bellow), koji je Ruždiju drag pisac i čiji romani ponekad pate od iste slabosti. 
kroz koju može da govori” (CHAUHAN 2001: 48), ${ }^{15}$ kao i da pripovedači jednim delom, neizbežno, izražavaju njegove stavove i osećanja, ali da ga zbog toga ne treba izjednačavati sa njima ili ih tumačiti autobiografski. Indikativno je da se Ruždi pri tome, kao i u prethodnom citiranom odlomku, poziva na Beloua i njegovog Hercoga, junaka istoimenog romana (Herzog), koji se, kao što ćemo videti, u drugoj formi javljaju kao značajan uticaj i u Ruždijevim memoarima:

[...] svaki put kada upotrebite pripovedača koji govori u prvom licu [...] deo vašeg iskustva, stavova, osećanja i strasti neizbežno izlazi kroz njegova usta i kroz njegovo iskustvo. To je istina. [...] Pa ipak, on nije ja. Mislim da se u slučaju kada pisci na vrlo prisan način koriste likove koji iznose svoju tačku gledišta često javlja pokušaj da se pisac poveže sa tim likom, ali Belou ipak nije Hercog (REDER 2000: 206). ${ }^{16}$

Međutim, kad je o memoarima reč, Ruždi je još u jednom intervjuu iz 1992. godine najavio da bi na osnovu svog iskustva iz vremena fatve i potonje afere mogao da napiše samo nefikcionalnu knjigu, jer takvu građu zanimljivom čini isključivo to što je u pitanju istina (CHAUHAN 2001: 119). Ruždi zatim istu ovu tvrdnju ponavlja i u samim memoarima (JA 340-341, DŽA 324).

U informativnom članku o tankoj liniji koja razdvaja memoare i autobiografiju, Ijan Džek (Ian Jack), kolumnista Gardijana (The Guardian), a u periodu od 1995. do 200\%. i urednik prestižnog književnog časopisa Granta (Granta) koji je doprineo Ruždijevoj popularizaciji, napominje da se naziv „memoari” danas koristi češće nego „autobiografija” i da je granica između ovih žanrova nejasna, ali da ipak postoje razlike:

15 "it's quite easy for a writer to have a figure through whom he can speak."

16 "[...] every time you use a first person narrator [...] then inevitably a chunk of your experience and your attitudes and your feelings and passions will come out through his mouth and will come out through his experience. That's true. [...] However, he ain't me. And I think it's often the case when writers have used point of view characters in a very intimate way that there is an attempt to associate them, and yet Bellow is not Herzog." 
Srđan Simonović: Džozef Anton Salmana Ruždija: izmedu memoara, autobiografijje...

Autobiografija obično predstavlja svedočanstvo o nečijim dostignućima. Pišu je, sami ili uz nečiju pomoć, raznorazni ljudi, uglavnom oni manje ili više slavni: fudbaleri, političari, spikeri. Ali nečija dela, slava i zanimljiv život nisu nužni sastojci memoara.

Memoari imaju ambiciju da budu zanimljivi sami po sebi, kao što bi bio neki roman o intimnom, ličnom iskustvu. Obično se teži tome da se memoari smatraju „književnim” delom i stoga njihovi autori pozajmljuju brojne književne trikove - trikove preuzete iz romana, iz fikcije - jer u memoarima postoji želja da prošlost ne bude samo zabeležena, već vaspostavljena. Da bi bili uspešni u tom smislu, u skladu sa tezom da je svačiji život zanimljiv ako se prikaže kako treba, memoari moraju da budu dobro napisani (JACK 2003: n.pag.). ${ }^{17}$

Kao iskusan pisac fikcionalnih dela, Ruždi u svojim memoarima nije morao ni od koga da pozajmljuje književne postupke, jer se njima redovno služi u svom osnovnom spisateljskom radu. Možda zato i nije čudno što postoji formalna i sadržinska sličnost Džozefa Antona sa Ruždijevim romanesknim obrascem. Robert Iglston je već zapazio neka tematska i formalna poklapanja između memoara i drugih Ruždijevih dela, a njegovi zaključci osim romana impliciraju i piščeve eseje (EAGLESTONE 2013: 117). Uz osvrt na Iglstonove najvažnije argumente, sada ćemo razmotriti pomenutu osobenost Ruždijevih memoara.

Pre svega, paradoksalno je da se Ruždi, kada mu se pružila prilika da sasvim otvoreno i opravdano piše koliko hoće u svoje lično ime, opredelio za pripovedanje u trećem licu. Ruždi objašnjava zašto se odlučio na taj potez u intervjuu sa Džonom Frimanom (John Freeman), urednikom časopisa Granta:

17 "An autobiography is usually a record of accomplishment. All kinds of people, more or less famous, can write them or be helped to write them: footballers, politicians, newsreaders. Deeds, fame and an interesting life are not necessary ingredients of the memoir.

The memoir's ambition is to be interesting in itself, as a novel might be, about intimate, personal experience. It often aspires to be thought of as "literary", and for that reason borrows many of literature's tricks - the tricks of the novel, of fiction - because it wants to do more than record the past; it wants to re-create it. If a memoir is to succeed on those terms, on the grounds that all lives are interesting if well-enough realised, the writing has to be good." 
$D \check{F} F$ : Jedna od najupadljivijih stvari u vezi sa ovom knjigom jeste da ona, premda je reč o memoarima, prilikom čitanja ostavlja utisak kao da je u pitanju biografija, delom zbog toga što je napisana u trećem licu. Zašto ste tako postupili?

SR: (a) Probao sam prvo lice i nije mi se dopalo. (b) u ovoj knjizi, pitanje identiteta je važno; bilo je toliko Ruždija koje su drugi ljudi izmislili... a mislim i da sam hteo da kažem da ja nisam sasvim ista osoba kao taj ,ja” o kome se u knjizi govori. Autor je sada staloženiji i dve decenije stariji; subjekat knjige je mladi i pod stresom koji dovodi do raznih izobličavanja (RuSHDIE and FREEMAN 2012: n.pag.). ${ }^{18}$

Bez obzira na ovo obrazloženje, pripovedanje u trećem licu, kako Iglston zapaža, približava memoare fikciji. Čak i sam naslov knjige, piščev pseudonim, odnosno fikcionalno ime koje upućuje na književne uzore (Džozefa Konrada (Joseph Conrad) i Antona Pavloviča Čehova), ukazuje da nije reč o konvencionalnim memoarima (EAGLESTONE 2013: 116).

Kao moguće objašnjenje te činjenice, Iglston upućuje na Ruždijevu tvrdnju da ga u fikciji interesuje granično područje između različitih oblasti ili nivoa iskustva: sna i jave, mašte i stvarnosti, prošlosti i sadašnjosti. On zatim ukazuje da se Ruždi u memoarima u nekoliko navrata služi postupcima iskrivljavanja stvarnosti ili zamagljivanja granice između realnih događaja i fikcije, iako je Džozef Anton, makar nominalno, dokumentarno delo u kome se govori o realnim događajima (EAGLESTONE 2013: 119-121).

Na primer, Ruždi/pripovedač u toku afere izazvane fatvom počinje da u mislima sastavlja na stotine imaginarnih pisama koja ne može da pošalje, poredeći se sa Belouovim Hercogom koji to takođe

18 "JF: One of the most striking things about this book is while it's a memoir, it reads like a biography. Partly because it is writing in the third person. Why did you do this?

SR: (a) I tried the first person and didn't like it. (b) the question of identity is important in this book; there were so many Rushdies being made up by other people ... and, I think, I wanted to say, I'm not quite the same person as the 'me' about whom the book is written. The author is now in a calmer frame of mind, and two decades older; the subject is younger, and under all sorts of deforming stress." U prevodu smo zadržali format izvornika, uključujući kapitalizaciju i upotrebu kurziva. 
Srđan Simonović: Džozef Anton Salmana Ruždija: izmedu memoara, autobiografije...

čini (JA 185, DŽA 178). Neka od tih pisama zatim se pojavljuju u tekstu memoara. Ona su isprva upućena redakcijama određenih medija, pojedinim novinarima, javnim ličnostima i političarima, ali se među njih odmah umeće i jedno naslovljeno Robinzonu Krusou (JA 187, DŽA 180), da bi se vremenom, baš kao i u Belouovom romanu, umnožila pisma upućena apstraktnim primaocima, kao što su Bog (JA 282-283, DŽA 268-269), Religija i Čitalac (JA 315-316, DŽA 299-301), a javlja se i Ruždijeva fiktivna i šaljiva prepiska sa samim sobom, ali trinaest godina mladim (JA 584-585, DŽA 552). Kada Ruždi u memoare uključuje kratku prepisku sa Haroldom Pinterom (Harold Pinter, JA 543-544, DŽA 517-518), koji mu je prijatelj, a u kojoj dvojica pisca pokušavaju da izglade nedavni nesporazum, situacija se usložnjava, tako da Iglston s pravom postavlja pitanje kako treba da razumemo tu prepisku, budući da su ova pisma štampana kurzivom kao i ostala koja nisu mogla biti poslata. Da li je, dakle, reč o stvarnim ili imaginarnim pismima? (EAGLESTONE 2013: 120-121). Čitaocima je prepušteno da sami pronađu odgovor na to pitanje.

Još jedan upadljiv primer narušavanja konvencionalnog realističkog postupka je piščev opis konačnog raskida sa svojom četvrtom ženom, Padmom Lakšmi (Padma Lakshmi), koja napušta Ruždija i odlazi sa starijim, enormno bogatim muškarcem koga Ruždi opisuje kao Baju Patka iz Diznijevih (Walt Disney) stripova, preuzimajući tipičnu i prepoznatljivu stripovsku ikonografiju. Pripovedač konstatuje da je Padma iščezla iz njegovog života

[...] ne u oblaku zelenog dima kao Zelena veštica sa Zapada, već u privatnom mlaznjaku nekakvog metuzalema Baje Patka, i otišla u njegov privatni svet smešten na Tužnim brdima i drugim mestima ispunjenim beznađem i lovom. Posle osam godina tokom kojih mu je u proseku bar jednom nedeljno govorila da je prestar za nju, završila je sa dvesta godina starijim patkom, možda zbog toga što je Baja Patak mogao da otvori začarana vrata koja su joj omogućavala ulazak u njen sopstveni tajni svet iz mašte, svet beskrajnih privilegija, u život bez ikakvih ograničenja koji se vodio na Velikoj dembelplanini-šećerlemi, gde ptice poje i pčele se roje i na drveću cigarete zru; kao i zbog toga što je u privatnim odajama njegovog privatnog, divnog dvora za pir u Patkovgradu, SAD, postojao bazen za kupanje pun zlatnika, gde su mogli da se odbace sa niske odskočne daske, zarone i plivaju satima onako 
kako je Čika Baja voleo da pliva, u okrepljujućoj likvidnosti svog novca; [...] u podrumu njegovog privatnog dvorca nalazio se Dijamant veliki kao hotel „Ric”, a u pećini u srcu Patkovske planine, koju je kupio u smelom investicionom udaru izvedenom još davno, u doba jure, kada je bio tek mlađahno pače od svojih sedamdesetak leta, njegov pripitomljeni tiranosaurus je, rame uz rame sa vernim velociraptorima, čuvao od svih kradljivaca ovoga sveta njegovo basnoslovno zmajevo blago, njegovu privatnu hrpu novca kome broja nema (JA 590; [DŽA $55 \%]){ }^{19}$

Pripovedačev zaključak je lakonski: „Posle njenog odlaska u taj izmaštani svet, stvarnost se vaspostavila" (JA 590-591; [DŽA 558]). ${ }^{20}$ Nave- $^{-}$ deni odlomak obeležavaju izrazita ironija i satira, uz mnoštvo intertekstualnih referenci u kojima se mešaju izvori iz različitih medija. „Otvoriti začarana vrata” koja vode u svet mašte, zemlja Dembelija i zmajevo blago asociraju na svet bajki. Tu su zatim nezaobilazne aluzije na klasična književna dela: „divni dvor za pir” je naravno ”pleasure dome” iz Kolridžovog „Kublaj Kana”(“Kubla Khan”), koji prenosimo u nenadmašnom prevodu Ranke Kuić, a „Dijamant veliki kao hotel 'Ric” ("The Diamond as Big as the Ritz")je poznata pripovetka Frensisa Skota Ficdžeralda (Francis Scott Fitzgerald). Reference iz domena film-

19 "...] not in a green puff of smoke like the Wicked Witch of the West but in some ancient Scrooge McDuck's private jet, into his private world at Dismal Downs and other places filled with wretchedness and cash. After eight years during which she had told him once a week on average that he was too old for her, she ended up with a duck who was two hundred years older, perhaps because Scrooge McDuck could open the enchanted door that allowed her into her own secret dreamworld of infinite entitlement, of life lived with no limits on the Big Rock Candy Mountain with the birds and the bees and the cigarette trees; and because in a private room of a private pleasure dome in Duckburg, USA, there was a swimming pool filled with golden doubloons and they could dive off the low springboard there and swim for hours as Uncle Scrooge liked to swim, in the soothing liquidity of his money; $[. .$.$] in the basement of his private castle was the Diamond as Big as the$ Ritz, and in the cave at the heart of Duck Mountain, which he had bought in a venture-capitalist coup long ago in the Jurassic era when he was just a young duckling of seventy summers or so, his tame tyrannosaurus flanked by his loyal velociraptors guarded from all marauders his fabled dragon hoard, his private uncountable stash."

20 "Once she had gone away into the world of make-believe, reality returned." 
ske umetnosti, od Zle veštice sa Zapada iz Ruždiju dragog Čarobnjaka iz Oza (The Wizard of Oz) do dinosaurusa iz Parka iz doba Jure (Jurassic Park), smenjuju se sa onima iz stripa: Tužna brda i Patkovgrad su toponimi iz stripova o Baji Patku, osnovne matrice iz koje Ruždi crpe svoje metafore - Baja Patak je matori milijarder, poslovična tvrdica i patološki srebroljubac koji u slobodno vreme voli da se kupa u bazenu punom zlatnika. Najzad, Ruždi u svoj tekst ugrađuje i nekoliko stihova iz popularne američke folk pesme iz dvadesetih godina prošlog veka, „Velika dembel-planina-šećerlema” "The Big Rock Candy Mountain”), koje slobodno prevodimo u duhu navedenog odlomka. Pri svemu tome nikada ne saznajemo kako se novi muž Padme Lakšmi stvarno zove, čime se bavi ili gde živi, osim što u američkoj saveznoj državi Juti zaista postoji planina koja se zove „Velika planina-šećerlema" ("the Big Rock Candy Mountain"), ali i taj toponim je povezan sa istoimenom pesmom, pa je teško pretpostaviti da Ruždi njime upućuje čitaoca na ma koju stvarnu lokaciju. U pitanju je postupak tipičan za Ruždija-romansijera: umesto konvencionalnog realističkog opisa u kome bi prosto bili izloženi stvarni događaji, kao što bismo očekivali od memoara, pisac koristi isključivo sugestivno figurativno izražavanje, jer, paradoksalno, baš kao što je to čest slučaj i u Ruždijevim fikcionalnim delima, realni doživljaj i osećanja Ruždija/pripovedača istinitije su izraženi ne-realističkim pripovednim sredstvima, pomoću niza preteranih ali utoliko upečatljivijih metaforičkih slika.

Osim ovih pojedinačnih epizoda, između Džozefa Antona i Ruždijevih najpoznatijih romana postoji upadljiva sličnost u pogledu opšte vremenske strukture. Radnja memoara počinje in medias res, na dan objavljivanja fatve, koji je prikazan u prologu od petnaestak strana. Zatim pripovedač u prvom poglavlju knjige retrospektivno izlaže svoj život od detinjstva do pisanja i objavljivanja Satanskih stihova, da bi se potom uglavnom držao pravolinijskog, hronološkog redosleda događaja. Isti narativni obrazac Ruždi koristi u većini svojih romana.

Povrh toga, Ruždi u memoare ugrađuje i dva upečatljiva metanarativna pasaža, ključeve za čitanje koji objašnjavaju zašto je knjiga koncipirana tako kako jeste, i to kako u pogledu postupka, tako i osnovne teme. U ovim odlomcima prepoznajemo dodatnu sličnost sa 
Ruždijevim fikcionalnim delima, koja najčešće sadrže i metanarativnu dimenziju.

Na početku VI poglavlja memoara, naslovljenog „Zašto je nemoguće fotografisati pampu" ("Why It's Impossible to Photograph the Pampas"), pripovedač prepričava anegdotu o slavnom argentinskom piscu Horheu Luisu Borhesu (Jorge Luis Borges) i fotografu Gustavu Torlihenu (Gustavo Thorlichen), za čiju je knjigu fotografija Argentine Borhes napisao predgovor. Razmišljajući o mogućnostima i ograničenjima fotografije, Borhes kao primer navodi argentinsku pampu i objašnjava da nijedna fotografija ne može da predstavi njene razmere. Jedini način da se pampa zaista doživi jeste u mašti putnika, odnosno u vremenu koje je potrebno da se prevali put preko tog ogromnog prostranstva. Mada Ruždi-pripovedač eksplicitno poredi period svog života opisan u memoarima sa položajem Borhesovog putnika koji sporo napreduje preko naizgled beskrajne ravnice, ova anegdota ima i dodatnu metatekstualnu funkciju, kao figurativni opis same knjige Džozef Anton, u kojoj se detaljno, iz dana u dan, opisuje mučan i jednoličan period kroz koji Ruždi prolazi: to je, naime, jedini način da i čitalac zaista doživi smenjivanje niza monotonih dana i događaja u piščevom životu (JA 337-339, DŽA 321-322).

Na drugom mestu, u upečatljivom poetičkom odlomku u kome se govori o nastanku Džozefa Antona, Ruždi rezimira suštinsku temu na kojoj se temelje njegovi memoari. On objašnjava svoju prvobitnu zamisao ovog dela kao knjige u kojoj bi opisao svoj položaj, ali ne u konvencionalnoj autobiografskoj formi:

Počeo je da razmišlja o projektu pod radnim naslovom „Inferno”, u kome bi mogao da pokuša da pretvori svoju priču u nešto više od obične autobiografije. Bio bi to halucinantni portret čoveka čija se slika sveta razbila. Kao i svako drugi, i on je nekada u glavi imao određenu koherentnu i smislenu sliku o svetu. Živeo je u toj slici, razumeo zašto je ona baš takva kakva je i umeo dobro da se u njoj snalazi. A onda, kao da je neko zamahnuo džinovskim maljem, fatva je razbila tu sliku u paramparčad, ostavljajući ga u apsurdnom, bezobličnom, amoralnom svetu u kome je opasnost pretila sa svih strana, a smisla nigde nije bilo na vidiku. Čovek iz njegove priče očajnički je pokušavao da sačuva svoju sliku sveta, da je održi u jednom komadu, ali njeni delovi su se odlamali poput krhotina razbijenog ogledala 
Srđan Simonović: Džozef Anton Salmana Ruždija: izmedu memoara, autobiografije...

i isekli mu dlanove do krvi. Pomračene svesti, u toj mračnoj šumi, čovek krvavih ruku, koji je bio verzija njega samog, krenuo je put svetlosti dana, kroz inferno, prolazeći kroz bezbroj krugova pakla, kroz privatni i javni pakao, i zalazeći u tajne svetove strave [...] (JA 340; [DŽA 323]).21

Iz daljeg teksta saznajemo da je Ruždi posle izvesnog vremena odustao od namere da pretoči svoje iskustvo u romanesknu formu i rešio da se drži memoarske proze, zaključivši da pomenuta priča ima smisla jedino zato što je istinita.

Pa ipak, osim podrazumevane paralele sa Danteovom Božanstvenom komedijom (Dante Alighieri, Divina Commedia), kratki opis te nenapisane knjige u stvari odlično apstrahuje osnovnu potku Ruždijevih memoara: oni jesu baš ta priča, ispričana kroz mnoštvo konkretnih, stvarnih događaja. Još je interesantnije da piščeva navodno neostvarena zamisao zapravo odgovara i fabuli nekoliko Ruždijevih romana, sažimajući njihov osnovni psihološki i egzistencijalni obrazac. Navedeni opis umnogome se podudara sa situacijom u kojoj se nalazi čitav niz Ruždijevih glavnih protagonista, među kojima su Lepršavi Orao u Grimusu (Grimus), Salim Sinaj u Deci ponoći, Saladin Čamča i Džibril Farišta u Satanskim stihovima, Moraiš Zogoibi u Mavrovom poslednjem uzdahu, Umid Merčant u Tlu pod njenim nogama (The Ground Beneath Her Feet), Šalimar i Bunji u Klovnu Šalimaru (Shalimar the Clown), otac i trojica braće Golden u Kući Goldenovih (The Golden

21 "He began to think of a project provisionally called 'Inferno' in which he could try to turn his story into something other than simple autobiography. A hallucinatory portrait of a man whose picture of the world had been broken. Like everyone he had had a picture of the world in his head that had made a kind of sense. He had lived in that picture and understood why it was the way it was, and how to find his way round inside it. Then like a great hammer swinging the fatwa smashed the picture and left him in an absurd formless amoral universe in which danger was everywhere and sense was not to be found. The man in his story tried desperately to hold his world-picture together but pieces of it came away in his hands like mirror shards and cut his hands until they bled. In his demented state, in this dark wood, the man with the bleeding hands who was a version of himself made his way towards the daylight, through the inferno, in which he passed through the numberless circles of hell, the private and public hells, into the secret worlds of terror $[\ldots] "$ 
House), kao i dečaci koji su junaci Haruna i mora priča (Haroun and the Sea of Stories) i Luke i vatre života (Luka and the Fire of Life). Svima njima se slika sveta usled nepovoljnih događaja razbija, a oni prolaze kroz krugove ličnog i/ili javnog pakla ne bi li se izvukli iz nezavidnog položaja u kome su se neočekivano obreli. Motiv razbijanja slike sveta najdirektnije je prikazan u Kući Goldenovih, u epizodi u kojoj jedna od junakinja romana, Rija Zakarijasen, u trenutku lične krize sanja san u kome se ova metafora konkretizuje. Kada se probudi, ona shvata njegovo simbolično značenje, jer je njena slika sveta zaista razbijena (RusHDIE 2017: 286, RuŽDI 2017: 291).

S obzirom na žanrovsku neodredenost Džozefa Antona, Jael Maurer ističe da se autor u memoarima vešto poigrava različitim žanrovskim konvencijama, ,od porodične drame do detektivskog trilera, od horora do komičnih ludorija pisca koji se skriva" i da na taj način iznova osmišljava formu memoara kao svojevrsne „hibridne konstrukcije” (MAURER 2014: 176). ${ }^{22}$ U kontekstu svoje studije o naučno-fantastičnoj dimenziji Ruždijevog dela, ova kritičarka u zaključku određuje Ruždijeve memoare kao uzorni primer takozvane „slipstrim” ("slipstream”) proze (Maurer 2014: 179-183). Pojam „slipstrim” skovao je američki pisac naučne fantastike Brus Sterling (Bruce Sterling) kao parodičnu analogiju sa engleskom rečju „mejnstrim” ("mainstream”) i naziv za prekoračivanje žanrova u naučnoj fantastici, ali i savremenoj književnosti uopšte. Slipstrim fantastika u najširem smislu izražava „čudno osećanje" koje u čoveku budi način života karakterističan za razvijenu civilizaciju na kraju XX i početkom XXI veka (SterLING 1989: $n$. pag., MAURER 2014: 181), a Sterling na kraju svog pionirskog teksta prilaže i spisak dela koja po njegovom sudu potpadaju pod ovu kategoriju. Taj spisak uključuje Borhesa, Gintera Grasa, Andželu Karter (Angela Carter), Tomasa Pinčona (Thomas Pynchon), pa i Ruždija (STERLING 1989: n. pag.). U jednom skorašnjem članku posvećenom fenomenu savremene „postžanrovske” književnosti, prvenstveno u kontekstu naučne fantastike, Kejt Maršal (Kate Marshall) iznosi tvrdnju da do

22 "from domestic drama to detective thriller, from horror to the comic antics of the author in hiding." "a hybrid construction". 
presudnog rušenja žanrovskih barijera dolazi upravo krajem prošlog veka, kada pisci koji se obično ne kategorizuju kao autori naučnofantastičnog žanra počinju da pozajmljuju postupke i trope karakteristične za naučnu fantastiku i da ih ugrađuju u svoja dela. Među primerima koje ona navodi nalaze se neka od najpoznatijih imena savrmene anglofone književnosti, kao što su Majkl Šejbon (Michael Chabon), Kormak Makarti (Cormac McCarthy), Tomas Pinčon i Margaret Atvud (Margaret Atwood, MarshaLL 2018: 80-81). Takvo shvatanje slipstrima približava se nekim određenjima postmodernističke književnosti, koja ima dodirnih tačaka sa naučnom fantastikom. ${ }^{23} \mathrm{U}$ pitanju je svakako jedno moguće tumačenje Ruždijeve uobičajene žanrovske mešavine, koje Jael Maurer lepo uklapa u svoju analizu celokupnog piščevog opusa. I pored toga, njeno čitanje Džozefa Antona kao reprezentativnog slipstrim teksta smatramo preteranim, jer je po našem sudu ipak prvenstveno reč o memoarima, u kojima se pisac u određenoj meri poigrava žanrovskim konvencijama. S druge strane, njena inovativna teza o Ruždijevoj bliskosti sa fenomenom slipstrima ima daleko više smisla kada su u pitanju Ruždijeva fikcionalna dela.

Pored specifične žanrovske mešavine, Ruždijeve memoare karakteriše značajna poetička dimenzija, koja je u kritici uglavnom ostala nepravedno zanemarena. Po našem sudu, pored čisto dokumentarističkog sloja, upravo piščevi autopoetički komentari čine najvredniji segment Džozefa Antona, jer je reč o knjizi koja u kontekstu Ruždijevog opusa predstavlja poetički iskaz prvog reda.

Kao izrazito samosvestan pisac, Ruždi je od početka karijere zaokupljen poetičkim pitanjima. Svoje poetičke stavove i opšte književne poglede najjasnije i najopširnije je formulisao u raznim nefikcionalnim tekstovima (člancima, esejima, književnim kritikama, predgovorima), koje redovno objavljuje od 1981. godine, kao i u pojedinim intervjuima. Istovremeno, poetičke preokupacije utkane su i u njegova fikcionalna dela, koja neizostavno sadrže i (auto)poetičke refleksije i komentare. Iako Ruždi nije izričito formulisao svoju poetiku u vidu nekog manifesta ili književnog programa, više njegovih eseja i čla-

${ }^{23}$ O tome v. McHale 2001: 59-76. 
naka koncipirano je kao neka vrsta „programskih” tekstova. Naročito je burna afera oko fatve prinudila Ruždija da opravdava svoje delo i obrazlaže svoj književni postupak još direktnije nego do tada. On to čini u nizu intervjua i polemičkih eseja, a najzad i u memoarima, koji su ujedno kulminacija i rekapitulacija piščevog višegodišnjeg javnog istupanja u duhu otpora i samoodbrane.

Međutim, osim polemičkog aspekta, Ruždijevi memoari nam zapravo nude dragocen uvid u piščevu „radionicu” i na jednom od nivoa funkcionišu kao Ruždijev svojevrsni lični „companion” - vodič i priručnik za tumačenje njegovog književnog dela. Džozef Anton sadrži niz zaokruženih autopoetičkih celina koje se mogu čitati i kao umetnuti eseji, pa su memoari u tom pogledu komplementarni sa piščevim ostalim nefikcionalnim delima i, kao takvi, zapravo najzanimljiviji proučavaocima Ruždijevog dela, a rekli bismo i običnim čitaocima. U knjizi se rezimiraju neke od glavnih tema i preokupacija koje Ruždi obrađuje u svojim romanima, kao i autobiografska građa koju je u njima upotrebio. Komentarišući sva svoja dotadašnja fikcionalna dela, Ruždi prevashodno daje dokumentaristički prikaz procesa njihovog nastanka. ${ }^{24}$

Satanskim stihovima je, prirodno, posvećeno najviše prostora. U memoare je ugrađen iscrpan autopoetički „esej” u kome Ruždi opisuje kako je ovo delo zamišljeno i napisano i eksplicitno objašnjava brojna pitanja umetnički obrađena u romanu. Polazeći od poznate priče o „satanskim stihovima” podmetnutim proroku Muhamedu, koja mu je dala početni podsticaj za pisanje romana (JA 40-45̆; DŽA 41-46), Ruždi zatim govori o genezi Satanskih stihova iz više različitih zamisli i objašnjava kako su se one najzad povezale i ispreplele u jedinstvenu celinu, odredivši time i specifičnu strukturu ovog dela (JA 68-73, 79; DŽA 69-74, 79).

${ }^{24}$ Ukratko su razmotreni Grimus (JA 50-5̌1, DŽA 51-502), Deca ponoći (JA 54-5\%, DŽA 55-58), Sramota (JA 60-61, DŽA 61-62), Harun i more priča (JA 167-169, DŽA 160-162), Mavrov poslednji uzdah (JA 290-291, 294-295, 301, 428-429, 431-432, 463-464; DŽA 276-277, 280, 286, 405-406, 408-409, 440-441), Istok, zapad (JA 430, DŽA 406-407), Tlo pod njenim nogama (JA 534-535, 553; DŽA 508, 527) i Bes (JA 595-596, DŽA 562-563). 
Za sagledavanje Ruždijeve poetike, ali i opšteg pogleda na svet, važni su takođe oni delovi memoara koji su posvećeni fatvi i piščevoj argumentaciji iznetoj povodom sukoba sa radikalnim islamistima. Ruždi beleži izricanje i objavu fatve (JA 1-16, 134-135; DŽA 7-20, 130131) i umeće u narativnu potku tri povezana esejistička pasaža koji se, kao i u slučaju poetičkih iskaza, zapravo spajaju u jedan celovit esej na temu islamskog fundamentalizma kao nove totalitarne ideologije. ${ }^{25}$

Što se tiče opštih (auto)poetičkih tema kojih se Ruždi u memoarima dotiče, ovde ih ne možemo sve detaljno razmotriti, već se moramo zadovoljiti time da ih samo letimično pobrojimo.

Ruždi u Džozefu Antonu piše o svom preispitivanju ličnog identiteta, specifičnom položaju pisca-migranta i dilemama vezanim za pitanje „autentičnosti” njegovog glasa zbog odluke da, kao predstavnik indijske dijaspore, stvara na engleskom jeziku ( $J A ~ 53-54$, DŽA 54-55; JA 98-99, DZ̈A 95-96; JA 294-295, DŽA 280). On se takođe osvrće na različite književne tradicije koje baštini, uključujući indijsko i persijsko pripovedno nasleđe $(J A 19, D \check{Z} A$ 21) i uticaj usmenih pripovedača na njegov postupak ( $J A$ 80-81, DŽA 81), a ističe i svoje opredeljenje za alternativnu ,veliku tradiciju” nasuprot klasičnoj livisovskoj, odnosno realističkoj školi (JA 342, DŽA 324-325).

Svoje pretežno negativne stavove o književnoj kritici i kritičarima Ruždi iznosi opisujući nekoliko odvojenih epizoda, koje obuhvataju njegovu odluku da prestane da se bavi pisanjem prikaza kako se ne bi zamerao drugim piscima ( $J A$ 111-112, DŽA 108), iskustvo učešća u književnom žiriju (JA 366-367, DŽA 348) i obračun sa uticajnim kritičarom Džejmsom Vudom (James Wood, JA 367, DŽA 349; JA 574-575, DŽA 542-543). Ruždi najzad usputno izražava i svoju netrpeljivost prema akademskoj književnoj kritici ( $J A$ 442, DŽA 419), te rešenost da konačno raskrsti sa književnim kritičarima kao takvima (JA 618-619, DŽA 583).

Kad je reč o odnosu književnosti i politike, Ruždi u Džozefu Antonu u anegdotskom tonu prepričava događaj sa 48. međunarodnog kongresa PEN centra, održanog u Njujorku u januaru 1986. godine,

$\overline{25}$ JA 343-346, DŽA 325-328; JA 356-357, DŽA 338-339; i JA 360-361, DŽA 342. 
gde je sticajem okolnosti bio uvučen u kratku raspravu između Sola Beloua i Gintera Grasa o društvenoj ulozi pisaca. Tom prilikom, Ruždi je na Grasov podsticaj izašao za govornicu i pitao Beloua otkuda to da su se američki pisci odrekli zadatka da pišu o ogromnoj moći svoje države u današnjem svetu. Belou mu je na to uvređeno odvratio da američki pisci nemaju zadatke, već se rukovode svojim nadahnućem (JA 77, DŽA 77-78). U pitanju je epizoda koju Ruždi očigledno smatra veoma značajnom, budući da se vraća na nju u više tekstova, ${ }^{26}$ a njena dodatna važnost proističe iz činjenice da je Ruždi kasnije praktično preuzeo na sebe ono što je nazvao zadatkom američkih pisaca, prikazujući američko društvo iz satiričnog ugla u nekoliko svojih romana (Tlo pod njenim nogama, Bes, Klovn Šalimar i Kuća Goldenovih).

Śtaviše, pitanje angažmana za Ruždija se preklapa sa njegovim poimanjem same prirode književnosti. Pred kraj memoara, u još jednom esejističkom pasažu, Ruždi rekapitulira svoje viđenje ljudske prirode, savremenog društva, piščeve uloge, suštine književnosti i romana kao književne forme (JA 626-630, DŽA 590-593). Rezimirajući neka od svojih osnovnih poetičkih načela, Ruždi ovde u humanističkom tonu iznosi konačnu apologiju svog književnog projekta, ali i odbranu dostojanstva književnosti kao takve. Ovaj završni poetički „esej” u Džozefu Antonu ujedno je i najsličniji Ruždijevim ranije objavljenim „programskim” esejima koji su pisani sa istim motivima i objavljeni u njegovim zbirkama nefikcionalnih tekstova Imaginarni zavičaji (Imaginary Homelands) i Predi ovu crtu.

U nastojanju da što jezgrovitije izrazi svoje shvatanje suštinskog smisla i funkcije književnosti, Ruždi naglašava njen otkrivalački i oslobodilački potencijal:

Književnost pokušava da otvori univerzum, da poveća, makar i malo, zbir onoga što je moguće da ljudska bića uvide i shvate i, na kraju, onoga što mogu da budu. Velika literatura odlazi do granica poznatog i trudi se da

${ }^{26}$ Odlomak memoara u kome se govori o kongresu PEN-a prethodno je u neznatno drugačijoj verziji objavljen kao zaseban članak u Njujork tajmsu (The New York Times, Rushdie 2005). V. takođe Ruždijev intervju sa Sedž Tomson (Sedge Thomson) iz marta 1987. godine (Chaunan 2001: 75-76). 
pomeri granice jezika, forme i mogućnosti, da bi svet mogao da oseća da je veći i širi nego ranije (DŽA 5991).27

Pominjući potrebu da se „otvori univerzum”, Ruždi aludira na frazu iz Belouovog romana Dekanov decembar (The Dean's December), koju je usvojio kao neku vrstu svog gesla, odnosno načela kojim se rukovodi u spisateljskom poslu (CHAUHAN 2001: 288). ${ }^{28}$ U Ruždijevom tumačenju, ova rečenica znači - proširiti granice, osvajati nove slobode, opisivati novu stvarnost, ponuditi nove kombinacije i mogućnosti. Formalna inovativnost, iako sama po sebi nužna, za Ruždija je pri tome neodvojiva od političkog angažmana, shvaćenog u najširem smislu. Uloga književnosti oličena je u njenoj etičkoj, pa time i društvenoj i političkoj dimenziji. Ruždi u nsatavku argumentacije navodi primere pesnika iz prošlosti koji su se suprotstavili tiranima i zbog toga ispaštali - Ovidija (Publius Ovidius Naso), Mandeljštama (Осип Эмильевич Мандельштам) і Lorku (Federico García Lorca). I pored nezaštićenosti samih pesnika, koji su izloženi ličnom stradanju, njihova poezija nadživljava surove imperije i totalitarne režime. Ruždi zatim podseća na podršku koju je tokom afere oko fatve dobijao od drugih umetnika i pisaca, da bi u zaključku naglasio da je sada na njega red da nastavi da pruža podršku drugima „koji pomeraju granice, vrše prestupe, a takođe i onima koji čine svetogrđe; svim onim umetnicima koji ne dopuštaju ni moćnicima ni verskim velikodostojnicima da povuku crte u pesku i narede im da te crte ne prelaze" (JA 628; [DŽA 592]). ${ }^{29}$

Krajnja (po-)etička poruka Ruždijevih memoara, formulisana $\mathrm{u}$ istom duhu, možda je još upečatljivije izražena u jednom ranijem

27 "Literature tried to open the universe, to increase, even if only slightly, the sum total of what it was possible for human beings to perceive, understand, and so, finally, to be. Great literature went to the edges of the known and pushed against the boundaries of language, form and possibility, to make the world feel larger, wider than before" (JA 628).

28 Istim citatom iz Belouovog romana Ruždi takođe završava svoj „programski” poetički tekst „Imaginarni zavičaji” iz istoimene knjige (RushdiE 1992: 21).

29 " $[. .$.$] who pushed bondaries, transgressed and, yes, blasphemed; all those artists$ who did not allow men of power or the cloth to draw lines in the sand and order them not to cross." 
odlomku Džozefa Antona. Komentarišući već pomenuti kongres PEN Centra iz 1986. godine, Ruždi napominje da je u to vreme za pisce još uvek bilo prirodno

da polažu pravo na to da budu, kao što je Šeli rekao, ,nepriznati zakonodavci sveta”, da veruju da je književna umetnost prava protivteža u odnosu na moć, i da doživljavaju književnost kao plemenitu, transnacionalnu, transkulturalnu silu koja je, u Belouovoj izvrsnoj formulaciji, u stanju da „malo više otvori univerzum”. Dvadeset godina kasnije, u svetu koji je postao zaglupljen i zaplašen, bilo je mnogo teže da se običnim majstorima reči pripiše tako uzvišena uloga. Teže, ali verovatno ništa manje potrebno (JA $78 ;\left[\right.$ [DŽA 78]). ${ }^{30}$

Osim što efektno poentira svoj stav, Ruždi zaista nastoji da takvo shvatanje zadatka književnosti ostvari u sopstvenim fikcionalnim delima, pa i u memoarima. Verujemo da mu na najuspelijim stranicama to i polazi za rukom.

\section{IN MEMORIAM}

Ovaj rad posvećen je uspomeni na profesora engleske književnosti Dr Slobodana Vukobrata, posebno imajući u vidu njegovo kontinuirano čitalačko i profesionalno interesovanje za dokumentarističke prozne žanrove kao što su biografija, autobiografija i memoari.

30 "[...] in 1986 it still felt natural for writers to claim to be, as Shelley said, "the unacknowledged legislators of the world', to believe in the literary art as the proper counterweight to power, and to see literature as a lofty, transnational, transcultural force that could, in Bellow's great formulation, 'open the universe a little more'. Twenty years later, in a dumbed-down and frightened world, it would be harder to make such exalted claims for mere wordsmiths. Harder, but no less necessary, perhaps." Navod iz Šelijeve Odbrane poezije (Percy Bysshe Shelley, A Defence of Poetry) dat je u prevodu Ranke Kuić. 
Srđan Simonović: Džozef Anton Salmana Ruždija: izmedu memoara, autobiografijje...

\section{IZVORI I CITIRANA LITERATURA}

Chauhan, Pradyumna S. (ed.). Salman Rushdie Interviews: A Sourcebook of His Ideas. Westport, CT: Greenwood, 2001.

Eaglestone, Robert. "Po-fa: Joseph Anton." Robert Eaglestone and Martin McQuillan (eds.), Salman Rushdie: Contemporary Critical Perspectives. London: Bloomsbury, 2013.

Hamilton, Ian. "The First Life of Salman Rushdie." The Trouble with Money and Other Essays. London: Bloomsbury, 1998, 95-138.

Joshi, Priya. In Another Country: Colonialism, Culture, and the English Novel in India. New York: Columbia University Press, 2002.

KuorTTI, Joel. "In Search for Lost Portraits: The Lost Portrait and The Moor's Last Sigh." Ana Cristina Mendes (ed.). Salman Rushdie and Visual Culture: Celebrating Impurity, Disrupting Borders. Abingdon and New York: Routledge, 2012, 70-86.

McHale, Brian. Postmodernist Fiction. Routledge: London and New York, 2001 [1987].

Marshall, Kate. "New Wave Fabulism and Hybrid Science Fictions." Rachel Greenwald Smith (ed.). American Literature in Transition 2000-2010. Cambridge: Cambridge University Press, 2018, 76-87.

Maurer, Yael. The Science Fiction Dimension of Salman Rushdie. Jefferson, NC: McFarland, 2014.

Mishra, Pankaj. "Anatomy of an Anti-Novel." Outlook, 22 March 1999: n.pag. https://www.outlookindia.com/magazine/story/anatomy-of-an-antinovel/207164). [21. 2. 2018.]

Orsini, G.N.G. "Coleridge and Schlegel Reconsidered." Comparative Literature 16 (1964): 107-111.

Popović, Tanja. Rečnik književnih termina. Drugo izdanje. Beograd: Logos Art/Edicija, 2010.

Reder, Michael R. (ed). Conversations with Salman Rushdie. Jackson, MS: University Press of Mississippi, 2000.

Rushdie, Salman. The Golden House. London: Jonathan Cape, 2017.

RushDie, Salman. Imaginary Homelands: Essays and Criticism 1981-1991. London: Granta/Penguin, 1992.

Rushdie, Salman. "Introduction." Daniel Hahn and Margarita Valencia (eds.). Lunatics, Lovers and Poets: Twelve Stories after Cervantes and Shakespeare. High Wycombe and Los Angeles: And Other Stories and Hay Festival of Literature, 2016, 7-11. 
Rushdie, Salman. Joseph Anton: A Memoir. London: Jonathan Cape, 2012. Rushdie, Salman. "The PEN and the Sword." New York Times, 17 April 2005: n. pag. http://www.nytimes.com/2005/04/17/books/review/the-penand-the-sword.html. [14. 5. 201\%.]

Rushdie, Salman. Step Across This Line: Collected Nonfiction 1992-2002. New York: Random House, 2002.

Rushdie, Salman and John FREEMAN. "Salman Rushdie: Interview." Granta: The Online Edition. In Conversation, 3 October 2012, n. pag. https:// granta.com/interview-salman-rushdie/s. [25. 9. 2018.]

RuŽDI, Salman. Džozef Anton: Memoari, prev. Srđan Krstić. Beograd: Vulkan, 2013.

RužDI, Salman. Kuća Goldenovih, prev. Ljiljana Petrović Vesković. Beograd: Vulkan, $201 \%$.

Schwalm, Helga. "Autobiography." Paragraph 1-28. Peter Hühn, et al. (eds.). the living handbook of narratology. Hamburg: Hamburg University, 2014. http://www.lhn.uni-hamburg.de/article/autobiography. [14. 11. 201\%.]

WALLART, Kerry-Jane. "Affinities, or the Hybrid Art of Perspective in Salman Rushdie's The Enchantress of Florence." Vanessa Guignery, Catherine Pesso-Miquel and François Specq (eds.). Hybridity: Forms and Figures in Literature and the Visual Arts. Newcastle: Cambridge Scholars, 2011, 213-222.

Srđan Simonović

\section{SALMAN RUSHDIE'S JOSEPHANTON: A CROSS BETWEEN MEMOIR, AUTOBIOGRAPHY AND POETICS}

\section{Summary}

In this article, Salman Rushdie's 2012 memoir Joseph Anton is analysed as a peculiar generic hybrid that blurs the distinction between the traditional memoir and autobiography. I next examine several elements that bring Joseph Anton close to Rushdie's fictional works, such as the book's temporal structure, the narrator's metanarrative commentaries and the occasional deliberate distortions of conventional realist technique. Finally, I discuss how the memoir provides Rushdie 
Srđan Simonović: Džozef Anton Salmana Ruždija: izmedu memoara, autobiografije...

with an opportunity to summarise and recap the literary views, values and poetics which lie at the heart of his oeuvre.

Keywords: Salman Rushdie, memoires, autobiography, poetics.

Univerzitet u Beogradu

Filološki fakultet

knesim@gmail.com 